\title{
The new challenges of organizing intellectual property in complex industries: a discussion based on the case of Thales
}

\author{
Ayerbe C., Lazaric N., Callois M., Mitkova L.
}

\begin{abstract}
:
The defence industries in France and elsewhere have, in recent years, undergone important technological, organizational and institutional changes that have profoundly altered their architectures. These changes have introduced a new division of labour bringing new opportunities for interaction leading to the creation of additional assets. In this context, the issue of protecting innovations and their exploitation has become central. Managing Intellectual Property Rights (IPR) requires industrial groups to draw on additional capabilities. This article analyzes these evolutions and focuses in particular on the new organizational arrangements that have accompanied them. Using the case of Thales, which in 2005 outsourced its Intellectual Property (IP), we answer questions such as: why should IP be outsourced; how should the outsourcing of IP activities be organized; and, how should capabilities involved in this new organizational arrangement be managed. These issues lie at the centre of this research and illustrate new challenges inherent to in-house and outsourced IPR management strategies.
\end{abstract}

Keywords:

Intellectual Property - Complex industries - Organization - Outsourcing - Case study

Classification JEL: 032 /034 


\section{1- INTRODUCTION}

The issue of Intellectual Property Rights (IPR) is increasingly important in the business sphere and in academic literature. This paper aims to contribute to this literature by focusing on the outsourcing of IPR activities. Until the mid-1990s, non-legal literature on IPR was limited both in scope and quantity (Hanel, 2006). The increasing interest in IPR is directly linked to the rise in patent applications during the 1990s, generally described as a patent surge (Neuhäusler, 2012). This is characteristic of intellectual capitalism, which results from the combination of a capitalist economy and a knowledge economy in which intellectual capital plays a major role and is considered as the principal economic asset (Granstrand, 2000). Over recent years, IPR management has become the cornerstone of corporate strategy and firms' competitive positioning (Hanel, 2006). Numerous studies have analyzed the reasons for this patent surge by outlining the various uses of patents (Blind et al., 2006). The first of these is obviously to protect the revenue from specific inventions. Recent research by Goldenberg and Linton (2012) refers to the compound option approach, which assesses the value associated with this primary motive to patent. From that perspective, a patent is primarily considered as an option to sue, "which in turn is an option to collect cash flows associated to winning the legal suit" (ibid, 181). But as mentioned by the authors, patents may offer other benefits, such as IP blockades, an extended market, increased reputation, exchanges and licensing potential. Often mentioned as Strategic Patenting, these alternative uses of patents are clearly responsible for the increase in applications and non-legal literature's interest in patents (Granstrand 2000; Hanel, 2006). For example, thanks to a textual analysis of the papers published in Technovation during 2009 and 2010, Linton (2011) points out that patents feature among the most frequently occurring terms (along with funding, absorptive capacity and alliance). More broadly, Candelin-Plamqvist et al. (2012) analyzed IPR articles published from 1970-2009 in the leading journals focusing on innovation management (the journal selection is based on Linton and Embrechts, 2007). This is the first study that systematically analyzes IPR research over a long period. As mentioned by the authors, it outlines the main trends in the fast-growing research field of IPR and enables researchers to position their studies better in terms of both method and content. Referring to this state of the art, our present research contributes to IPR literature in two ways. 
First, regarding methods, Candelin-Plamqvist et al. (2012) highlight the lack of recent studies at firm level. The authors mention that almost $90 \%$ of published studies have focused on macro-level and secondary data, and encourage new longitudinal and firm-level analysis that "may provide more feasible implications for innovation-management practitioners working on the organisational level" $(2012,508)$. They also call for more qualitative studies to answer how and why questions related to IPR issues. In the same vein, in his recent literature review on patent strategy, Somaya (2012) encourages case study research in order to improve the understanding of processes and mechanisms by which firms develop sophisticated patent management capabilities. In this context, our article tries to fill this gap by scrutinizing the organizational devices that accompany innovative firms. Based on a case study, we study the outsourcing of intellectual property (IP) and its implications for IPR management.

Secondly, regarding content, only very few studies have specifically focused on the question of organizing protection. The work done by Granstrand (1999), which constitutes an invaluable reference in the matter, only provides a very succinct treatment of outsourcing. Literature on IPR management has only recently specifically focused on outsourcing. Three major studies should be mentioned here: Reitzig and Wagner (2010), Mayer et al. (2012) and Moeen et al. (2013). These research studies are based on quantitative analyses and centre on the outsourcing of patent prosecution (activities related to filing and obtaining patents). They study the development of various types of human capital and their impact on outsourcing (Mayer et al., 2012), the hidden costs of outsourcing (Reitzig and Wagner, 2010) and the factors that influence the concentration of a firm's supply portfolio (Moeen et al., 2013). This present paper fits in with these recent published studies but takes a different methodological slant with a focus on firm level, thus aiming to gain a deeper understanding of how firms can organize themselves to manage their IPR. More specifically, it is based on an analysis of outsourcing, a kind of organizational arrangement that has been little explored in literature on IP management.

An analysis of the case of Thales, a French group in the defence industry that in 2005 opted to hand over the running of its IP to an external firm, provides a significant illustration. It offers a unique insight into an emerging model of IPR management. In France, new forms of governance and a new division of labour in the defence industry have led to the development of in-house technological capabilities aimed at better controlling the value chain (Hobday et al., 2005; Prencipe, 1997; Serfati, 2008). The distinction between state and private activities 
that resulted from a reform of the DGA (Délégation Générale pour l'Armement - military procurement agency) led to the emergence of new industrial groups (Guillou et al., 2008), and the creation of original types of partnerships to create new assets. This situation offers possibilities of hitherto unauthorized interaction, based on the creation of complementary assets. It totally modifies the issue of IPR and their management. The way that IP is organized typifies this renewal, and can lead to new types of coordination being put in place. We should point out here that IP comprises both industrial property (which includes patents) and the protection of literary and artistic works. This article focuses on protection by patent, which is only one aspect of IP. Our empirical data characterize the new division of activities to better comprehend the current issues involved in organizing protection. Protection, by nature, raises questions of confidentiality that a priori set it at odds with outsourcing, especially in the highly sensitive industry of defence. Why should IP be outsourced? How should the outsourcing of IP activities be organized, and how should the capabilities involved in this new organizational arrangement be managed? These are the questions that our research tackles. The answers to these questions will contribute to a better understanding of how to manage IPR activities.

To respond to these questions our article is divided into the following sections. In section 2, we present the theoretical framework, mobilizing transaction cost theory and the capabilities perspective. Section 3 presents the case of Thales and the evolution of the defence industry, which is representative of these transformations in terms of IP management. Section 4 provides the results of our empirical findings, notably organizational changes for supervising IPR in Thales. Section 5 discusses the theoretical and managerial implications of this research.

\section{2- LITERATURE REVIEW}

Some investigations highlight how IP is organized to fit in with R\&D strategy (Tsuji, 2002), or the growing trend for companies to manage IPR like an asset in its own right (Hanel, 2006). Research led by Granstrand (1999) focusing on major Japanese firms takes an original angle by presenting several possible ways of organizing IP. Although outsourcing is presented as one possible alternative, this issue is neither developed nor explained. An approach combining transaction cost and capability theories provides a useful analytical framework for understanding outsourcing (McIvor, 2009). This framework is used here in the particular case of outsourcing IP. 
Williamson's work on transaction costs (1998) has been widely developed to explain the motivations behind outsourcing. We should briefly mention here that a company looks for a suitable form of organization by comparing the costs generated by a transaction with a service provider with the costs of integration. The level of the transaction costs is determined by three critical factors: the specificity of the assets, the frequency of transactions, and the uncertainty. An activity is thus outsourced in the following cases:

- the service or product does not involve specific assets;

- the transaction does not occur too frequently;

- the uncertainty surrounding the transaction is low.

Among these attributes, the specificity of assets plays a large role in explaining the type of governance (McIvor, 2009). In fact, it is the idiosyncratic character of certain assets that warrants carrying out activities internally. On the other hand, assets with low specificity are more advantageously outsourced. In this field, some authors have illustrated that strategies in terms of outsourcing R\&D are also defined according to the specificities of innovation and technological assets (Huang et al., 2009). This specificity is particularly important in managing IPR, which involves knowledge of legal and technological aspects, and increasingly knowledge of strategic aspects (Ernst, 2003; Rivette and Kline, 2000). For instance, Herscovici (2008) shows that over the last twenty years, patents have more and more frequently been granted to inventors of processes. Rights may be granted, therefore, on the "virtual applications of a generic process" (e.g. computer algorithms). Patents are sought increasingly early on, making it difficult to evaluate their potential application. Granstrand (2000) also mentions that one of the most challenging problems in intellectual property is the "IP assembly problem". This means that products and services become more "multitechnological" (using new technologies but also combining more traditional ones). This has led to increasing interdependence between patents and businesses. Additional difficulty arises in the incorporation of the cumulative and systemic knowledge that is characteristic of complex industries (Hobday et al., 2000). The increased complexity of using IPR thus underlines the highly specific nature of IP and brings about new challenges as soon as the question of outsourcing arises. The study by Moeen et al. (2013) enriches this perspective. The objective is to analyze the portfolio of law firms (suppliers) used by client companies for outsourced patent legal work. The authors examine the factors that influence the concentration of a firm's supply portfolio (i.e. distribution among different suppliers). Five factors are identified to explain the outsourcing of patent filing activities. Among these factors, a close 
link emerges between significant firm-specific knowledge and a concentrated outsourcing of patent legal services into the hands of a few suppliers.

As well as transaction costs, a capabilities-based approach has also been widely used in literature to explain outsourcing. Indeed, beyond the necessary coordination between firms, in-house resources and capabilities also differentiate a company from its competitors and constitute a competitive advantage (Barney, 1991; Wernerfelt, 1984). More precisely, resources are defined as assets (tangible and intangible) that are specific to the company, and that it creates from generic production factors available on the market (Wernerfelft, ibid). In this context, outsourcing concerns activities that are not deployed internally "activities in which the organization lacks the necessary resources or capabilities internally can be outsourced" (McIvor, 2009: 47). The main difficulty for the company is therefore to define its core business, in as much as outsourcing aims to refocus capabilities towards this core and delegate activities considered as peripheral (Amin and Cohendet, 2004). This is a delicate task since the boundary between these activities is difficult to determine. Some studies show that firms can end up outsourcing apparently core activities (Mehta and Peters, 2007). The same is true for IP management, although in this area, outsourcing is more about balancing internal and external activities. Since the research done by Cassiman and Veuglers (2006), this question has been widely investigated in the case of managing $R \& D$ activities, but not protection (see in particular recent studies by Hagedoorn and Wang 2012, and Berchicci, 2013). Concurrent with the open innovation approach (Chesbrough, 2003), the increasing access to external knowledge and greater openness lead to managerial governance implications that have been under-analyzed by open innovation scholars (Felin and Zenger, 2013). Somaya (2012) clearly refers to "patent management capabilities" as a significant emerging field in literature that can help us understand how firms manage their patent choices and action, especially through outsourcing patent work.

It follows that corporations must learn to rapidly identify which IP activities should be outsourced so that their division of labour and IPR-management strategy can successfully coevolve. Abundant examples of this type of co-evolution exist, illustrating that paying particular attention to IPR has allowed some companies to develop their capital and, at the same time, has created institutional rules encouraging their development (Murman, 2003). A recent investigation by Roquilly (2009) provides useful insights in this direction. Roquilly (ibid) shows how Apple has built up a portfolio of legal resources designed to support its 
strategy, and how its legal capability fits in with existing rules of play. Indeed, Apple's strength lies in its ability to coordinate legal resources, like IPR, with technological resources. Nevertheless, creating and developing legal resources also brings new kinds of paradox, since resources, although they bring the company legal security, are also "potential generators of legal insecurity" (ibid). In other words, the more IPR a company accumulates, the higher the risk of entering into conflict with former rights. This is all the more difficult since the legal environment in which firms operate is marked by patent application procedures and mechanisms that have encouraged the development of long and costly litigation.

Ultimately, as pointed out by McIvor (2009), complementary approaches are needed to address the new ways of managing IPR, and in particular outsourcing. Transaction costs are more centred on organizational arrangements and their modes of governance. Capability analyses, on the other hand, start by looking at companies' differences in performance based on their prior know-how and resources. Intersecting these two approaches can throw light on the new ways of organizing IP. Our research therefore uses both of them here, especially in the technological environment of complex industries. In these industries, strategically using and organizing IPR calls for specific capabilities to identify and negotiate different rights between stakeholders. This enables the development of intermediaries, such as service organizations specialized in managing IPR, which play an increasingly active role in this new knowledge market (Lamoreaux and Sokoloff, 1996). These intermediaries (law firms) negotiate rights, which are an increasingly delicate process and far removed from the initial technological capabilities of industrial firms. Intermediaries rarely result from spin-offs, i.e. from an activity developed outside the company, but are more usually the fruit of distinct and complementary capabilities based on a specific legal profession. That is the reason why law firms of this type are generally unlikely to compete with industrial firms (Moeen et al., 2013). There is clearly therefore a division of labour between innovation stakeholders, with numerous intermediaries facilitating the transfer of property rights between innovation stakeholders, as well as ensuring the different stages of managing these rights for their clients. Our research is therefore situated in a context of specialized tasks linked to innovating activities. In the same vein, research done by Mayer et al. (2012) strongly contributes to the understanding of how a firm's different capabilities may emerge and influence the outsourcing decisions of patent legal work. The authors distinguish three types of human capital that are relevant for studying knowledge work activities: firm-specific human capital (knowledge and skills that are unique to a firm), industry-specific human capital (knowledge 
about the industry setting) and occupational human capital (knowledge and skills required to perform work within a professional or functional area). Their results show that firms prefer to outsource knowledge work in highly contested areas. As such they access the potentially higher occupational human capital of external suppliers. They recognize the value of law firms' occupational expertise, which is a major driver of outsourcing decisions for patents that are likely to be litigated and require the expertise of specialized suppliers.

Numerous works have recently studied the new division of labour between upstream suppliers, who license their IPR to downstream competitors, who in turn develop these technologies thanks to the complementary assets they possess (Gambardella and McGahan, 2009). Arora and Gambardella (2010) use the term Specialized Engineering Firms (SEF) to designate technology specialists who license their technologies to established firms. This new division of labour is characteristic of the Open Innovation Model, in which IPR plays a key role. SEFs therefore provide the opportunity to improve the creation of value (through inhouse organization and acquiring outside resources that intensify the value created) and to harness value (by licensing technologies to generate new revenue) (Chesbrough, 2003). This new division of labour has been studied in research dedicated to technological innovation rather than IP. Research by Reitzig and Wagner (2010) is the only contribution in this field to date. The authors distinguish the various activities of the IP value chain: IP generation (R\&D and creative works), IP protection (filing, enforcement), and IP exploitation (licensing, IP management). Their results show that "within the IP value chain, engaging in upstream patent filing increases the firm's ability to identify competitor patents" (ibid, 1191). In doing so, they outline the hidden costs of outsourcing, which reduce the opportunity for detecting IP competitors. However, the study is mostly based on patent filing activities. This emerging literature does not tackle the issues of managing IPR between industrial clients and their suppliers, and how to organize for outsourcing. Moreover, in accordance with Lowman et al. (2012), this literature shows no understanding of the management of IP outsourcing processes and the role of legal service organizations in creating value in the outsourcing process. This is precisely the object of our research.

\section{3- THALES FACED WITH A NEW DIVISION OF LABOUR}

\subsection{METHODOLOGY FOR DATA COLLECTION}


As we have just shown, the questions that arise regarding how to organize IP and in particular the decision to outsource have as yet been very little developed in existing research. Despite fruitful analyses of outsourcing based on transaction costs and capabilities, to our knowledge outsourcing has never been studied with a focus on how IP is organized. From that point of view this research is exploratory. Its new focal point is "theory building" as defined by Eisenhardt (1989). As Eisenhardt and Graebner (2007) indicate, this type of approach involves either relying on theory-driven research questions within an existing theoretical framework, or phenomenon-driven research questions that draw more from case work. This article is of the first type, with work on outsourcing being significant but not specifically focused on organizing IP. In this perspective, a qualitative study gives researchers an opportunity to grasp the context and benefits of the phenomenon studied (Eisenhardt and Graebner, ibid). From the existing qualitative research methodologies, we chose a case study approach, since it allows a subtle understanding of a specific question. Case study research has proved particularly suited to answering why and how questions (Yin, 2003) as addressed in the present study: Why should we outsource IP? How should the outsourcing of IP activities be organized? How should capabilities involved in this new organizational arrangement be managed? This research is based on a single case. According to Stake (1995), an in-depth study of a single case, with good access to data, gives the researcher "an opportunity to learn" from that particular case and understand the phenomenon studied. The choice of a single case can be justified when it is unusual (or rare), critical or revelatory (Yin, 2003). Our work involved analyzing some rare and until now little-studied phenomena as well as responding to some particularly innovating situations. Indeed, many firms and especially multinational corporations operate their IPR management both in-house and externally. They may, for example, hire an IP consultancy firm to manage international patents, follow up on annual instalments or provide specialist legal advice on a specific issue. This research, however, looks at setting up an outsourced form of IP, since in the case studied, Thales opted to get rid of its Industrial Property Department altogether. This was a fundamental strategic choice that modified the firm's scope of activity over the long term. Outsourcing of this kind might involve handing over one or more activities to another existing entity or a specially created entity. This amounts to a spin-off (Parhankangas and Arenius, 2003). From this point of view, in 2005 Thales adopted a new organizational arrangement unique in France when it made the decision to outsource its patents department to the consultancy firm Marks \& Clerk. 
In conducting our case study, we followed established guidelines for case study research (Einsenhardt, 1989; Stake, 1995; Yin, 2003). To this end, our research is based on documentary analyses and interviews held between 2004 and 2006. A number of interviews (17 in total) were made at Thales, including with IP managers, patent engineers and managers of Thales Business Units. An additional interview was held with the director of the company Marks \& Clerk. Part of this research received funding under the contract: "Typology of company skills linked to defence: analysis of codified and non-codified skills" for the OED (Economic Observatory for Defence, Ministry of Defence, OED/DAF/Ministry), a study commissioned in 2004 and delivered to the OED in 2008 (Guillou et al., 2008). The defence industry, in which Thales plays a major role in France, is presented below, followed by a description of the organizational transformations that have taken place within the group.

\subsection{STRUCTURE OF THE DEFENCE INDUSTRY}

Defence fits in with the now common definition of an industry based on complex technologies (Hobday et al., 2000). Industries that incorporate cumulative knowledge and systemic innovations (Dosi et al., 2008), such as computing and electronics, are typical of this growing technological complexity in which it is increasingly difficult, if not impossible, to isolate the contributions made by different companies. The systemic character of innovation complicates the issue of managing the associated IPR, in as much as one component of a system can be the object of multiple patents depending on its industrial applications. In theory, innovation could even be blocked by the appearance of innovators who master part of the system and restrict its access to rival and/or complementary companies (Arora et al., 2001). In fact, innovations based on complex technologies and products clearly exhibit the signs of a regime of weak appropriation such as defined by Teece (1986): cumulative technologies, problems relating to IP possession, and geostrategic imperatives modelling stakeholders' behaviour. These industries, like defence, integrate electronic sub-sets with software. However, finding ways to protect these (patents and royalties) results in numerous problems, a good illustration of which is the different appraisals made by the American patent office (USPTO-United States Patent and Trademark Office) and the European office (EPO European Patent Office) (Hanel, 2006). In practice, players in complex industries show a tendency to pool patents considered as essential, which are thus made accessible to partners of the pool, mainly with a view to establishing standards. More generally, at European level, the defence industry makes comparatively fewer patent applications than all other industries. 
In France, the defence industry has undergone numerous changes that have directly affected the way IPR is managed. For many years, IPR was negligible or neglected due to government intervention. A weak IPR culture has had a strong limiting effect on exchanges, and especially on spin-offs which, in the defence industry, define the transfer of military technology towards the civil domain, i.e. its initial application outside the frame in which it was originally conceived (Winebrake, 1992; Guichard, 2004). The reform of the DGA in 1997 and the separation of state and private activities constituted a new challenge for all stakeholders. Activities that came under the state were transferred to the private sector. The best-known example is the case of the Direction des Chantiers Navals (DCN), formerly an arsenal, that moved from being a state shipyard to a private firm controlled by Thales. The need to absorb new capabilities coming from public institutions and their increasing internationalization led to firms repositioning themselves (Guillou et al., 2008; Serfati, 2001) and made it necessary to define a new institutional framework, especially for IPR. The changes that came about in the 1990s redefined the rules of the game in France, the United Kingdom and the United States (Chinworth and Mowery, 1995), which led to a trial and error process to determine a framework of interactions that could be compatible with all objectives. The institutional arrangements put in place in Europe were at times very different, and in any case, far from optimal (c.f. for the United Kingdom, Mollas-Gallart and Tang, 2005).

In France, in general, the private contracting party obtains the intellectual property resulting from the contract. Contractual relationships between public and private entities are governed by the French Code on public markets. Intellectual property rights for public markets are described by article 111 of this code, and local authority markets by article 317 . In the case of R\&D contracts entered into by the DGA with private contracting parties, these contracts are specifically influenced by the Cahiers des Clauses Administratives Générales (CCAG), which can refer to intellectual or industrial services. The main difference regarding contractual relationships concerns the use of the services produced, rather than their property rights. The CCAG relating to intellectual services can be broken down into three options, examined here under:

- Option A is the most favourable for a public entity. In this case, the public entity can freely use the results of a service, reproduce them and communicate them to a third party (without specifications in the contract), and publish them provided they name the contracting party. Private contracting parties cannot make commercial use of 
them, communicate the results or publish them without the agreement of the public entity;

- Options B and C, unlike option A, assume that the public entity cannot use the results of services, even when partial, solely for its own purposes and those of a third party designated in the market. Option $\mathrm{C}$ differs from option $\mathrm{B}$ in as so far as the private contracting party can communicate the results of services to third parties and publish them under certain conditions.

The following diagram shows the different institutional frameworks that prevail in the three main defence industry nations.

\section{Insert Figure 1}

British DEFCONs, contracts under FAR (Federal Acquisition Regulation) and contracts under option B provide greater incentives in terms of contractualization. They confer intellectual property to the private contracting party, with the public entity holding an exclusive usage licence. These distinctions reveal different angles of attack in the levers used to promote dual technologies. The United States prefers to use contractual levers that incite the most recalcitrant companies to collaborate with the DoD (Department of Defense), while the UK prefers to implement duality within its own departments. DEFCON is the British acronym for Defence Contractual Terms and Conditions. Note that the US acronym is used for the alert system used by the United States armed forces (DEFense CONditions). There are five levels of alert, DEFCON 1 being the highest. The highest level ever reached was DEFCON 2 during the Cuban missiles crisis (a document explaining DEFCONs and intellectual property with the MoD (British Ministry of Defence) is available at http://www.ams.mod.uk/content/docs/ipr/iprguide.pdf).

In the French case, CRADA (Cooperative Research and Development Agreements), i.e. contracts made under option A, provide little incentive for industrials since the property rights of services lie with the public entity. For this reason, they were redefined in the mid-1990s to create a satisfactory IP policy at a time when companies were mutating and financialization was rife. It became indispensable to facilitate defence companies' internationalization and give them the means for a genuine IP strategy. This did not, however, involve stopping government funding for the industry, or renouncing the principle of autonomy (for a discussion on this point see Oudot, 2007; Oudot and Bellais, 2008). 
Consequently, the DGA's clarification of IPR at the end of the 1990s in favour of private companies (including in numerous domains the abandonment of joint user rights on assets developed during initial research programmes funded by the DGA) resulted in more autonomy for companies. Once the DGA had limited the recourse to secrecy and the settingup of joint user rights with private companies, it was easier for groups to develop their potential internationalization and patent portfolio (for a longer discussion see Serfati 2008). Within the DGA, this was achieved without the systematic abandonment of IP for this government agency.

\section{4- EMPIRICAL FINDINGS}

\subsection{THALES' IP STRATEGY}

Thales was created in 2000 when Thomson-CSF was split in two: Thales for defence and Thomson SA for the general public. Thales was therefore devised as an electronics company specializing in defence (50\%, including air systems, land, inter-army and naval systems), aerospace (25\%, including aeronautics and space) and security (25\%, including security solutions and services). In February 2010, the group was organized into seven divisions (avionics, land defence, space, air operations defence and security systems, defence mission systems and transport systems). In 2005, Thales moved closer to the DCN (formerly Direction de la Construction Navale) by acquiring $25 \%$ of its capital with the aim of consolidating its position in the military naval sector in Europe and creating the basis of a "naval Airbus". In 2007, thanks to an agreement with Alcatel-Lucent, Thales strengthened its technological capacities in some key areas: systems architecture, optics and advanced software. Since then, the group's objective has been to maintain its position as a global leader in electronics systems and defence. With a presence in 50 countries and a staff of 68,000, the group's turnover was 12.7 billion euro in 2008. In 2007, Alcatel-Lucent and Thales signed an agreement to transfer transport, security and space activities to Thales, along with an industrial agreement between the two groups: creation of the company Thales Alenia Space. In 2009, Dassault Aviation bought Alcatel-Lucent shares and entered into the capital of Thales to the level of $25.90 \%$. This led to reinforced electronic defence and defence telecommunications activities, but a slight move away from aeronautics defence systems. Thales pursues intense R\&D activity to which it devotes $18 \%$ of its turnover (around two billion euro), employing 25,000 researchers in leading-edge domains. This strong research 
activity is supported by numerous partnerships with universities and laboratories in Europe, the USA and Asia. More precisely, six technological fields form an integral part of Thales' core competencies: analysis, measurement and monitoring tools, telecommunications, computing, optics, electric components and audiovisuals. These six technological fields represent around $80 \%$ of its patent-filing activity and confirm the group's strategic position as an integrator of electronic defence and security systems.

The group's IP strategy aims to defend its markets, manage negotiations during disputes with third parties, and generate complementary revenues from development in the form of licences. The strategy has been somewhat modified following the changes mentioned above. The target of the former Thomson CSF company was to maintain its rank among the leading French patent filers. Since the group's split, with the exception of the aeronautics sector, there has been a drop in Thales's patent application activity. This can be explained by: the move in the trade towards integration systems; its specific position in a very broad range of technologies, which calls for a large number of electronics patent engineers who are in high demand; and increased staff mobility. In 2008, Thales possessed a portfolio of 13,000 patents covering 2,700 technological fields, maintained for an average duration of seven years. Different divisions of Thales apply for varying amounts of patents: the most active are the aerospace, telecommunications and electronics (equipment and civil defence) divisions, followed by antiaircraft defence and naval combat systems and lastly, security and services.

\subsection{A NEW ORGANIZATIONAL ARRANGEMENT FOR IP ACTIVITIES}

As mentioned above, in 2005 Thales adopted a new form of organization, taking the decision to outsource its patents department to the consultancy firm Marks \& Clerk. The motives for this reorganization were several:

- The main reasons were linked to human resources. Like all major industrial groups, Thales was faced with a lack of patent engineers on the job market and was unable to satisfactorily manage IP in-house. Incentive measures (including a bonus system for inventors) were fairly significant, but were unable to fill this gap;

- The company was aiming to cut costs by $20 \%$ to $25 \%$ over a period of 5 years;

- Another reason was to explore the potential for developing external services. This entailed setting-up an IP consultancy firm assured by an external firm working in relation with Thales. 
This outsourcing of Thales' IP activity in the form of an IP firm with a financial participation was a first in France. The firm's managers held $60 \%$ of the new entity, and the British partner Marks \& Clerk, a leading firm in patent and brand consultancy, held $40 \%$. It is worth pointing out that Thales' IP manager at the time directly oversaw the transfer of capacities by creating the Marks \& Clerk entity of which he has remained the manager.

Thales' former patents department employed 45 people. Department members moved on to new tasks: 32 staff joined the new Marks \& Clerk entity, 6 joined Thales' legal department, and 7 went to the technical department. The 32 members of staff who joined Marks \& Clerk were for the most part patent engineers, comprising 16 engineers, 1 lawyer and administrative support staff. Within Thales, the seven people that joined the group's technical department were put to work on the relationship between corporate policy and the technical departments of each of the six divisions (these are the "opinion givers"). One person is responsible for IP with the central laboratories (focused on initial research in several geographical zones). To improve links with researchers, IP correspondents (working part time) are designated to the 80 business units that make up these six divisions. This results in the following overall organization (c.f. Figure 2):

\section{Insert figure 2}

This new organization modifies the respective responsibilities of the different protection activities, including the decisions to file, develop and maintain patents. Some are still managed by Thales, while others have been totally handed over to Marks \& Clerk. Thales Corporate determines the group's IP strategy. It defines the application/abandonment strategy and patent development in collaboration with divisional IP managers and the laboratory IP manager. Thales Corporate also validates abandonment propositions. Thales retains the property of pending patents and patents abandoned by its subsidiaries. Many of Thales' overseas subsidiaries, e.g. in the UK, Netherlands and the USA, are financially autonomous when it comes to filing and maintaining their patents. Overall, IP strategy can be defined as opportunistic: it evolves in line with the work of different divisions, with some following a defensive strategy, and others remaining more focused on external development. The main aim of this strategy is to defend market share in core capabilities relating to the six technological domains that are the object of the most patented applications. The IP managers 
are in charge of linking Thales Corporate, the six divisions and the central laboratories. They are involved at two levels:

- They validate divisions' choices for patent applications;

- They coordinate Thales Corporate and its divisions on development decisions in the form of licensing (or cross licence agreements) and partnerships (joint-ventures, alliances, collaboration contracts, fusions and acquisitions).

The business units generate propositions for patent applications/renewals. Three main decisions are taken:

- The first of these concerns the choice of whether to file for a patent or keep the invention secret. The IP correspondent initiates applications and the business unit manager validates decisions. The IP correspondent in each business unit plays an intermediary role between inventors and division IP managers. Once the decision has been taken to file a patent, the IP correspondent contacts Marks \& Clerk so that a patent engineer can be designated in the firm to follow up on the evolution of $R \& D$ and make the legal application for the patent;

- The second level of decision relates to the renewal policy orientated by market change. In this case, the IP correspondent works directly with the product line managers (business managers). To formalize and improve the decision-making process on renewals, Thales creates specific committees (with secretariats outsourced to Marks \& Clerk) and tools to aid decision-making;

- The last decision concerns maintaining the patents. Each business unit organizes portfolio reviews every two or three years depending on the number of patents. The final decision is taken by the patent correspondent working in the business unit and validated by the division's IP manager.

The consultancy firm Marks \& Clerk provides operational support for Thales throughout the above-mentioned steps. It initially intervenes before the patent is filed, by proposing a patent engineer to follow up on the research, and then makes the first protection application. It is also responsible for writing up and following international applications. It implements Thales' decision in terms of development. During this step, it plays a "licensing support" role for the industrial group. Lastly, the Marks \& Clerk patent engineers intervene before the abandonment process by surveying the maintenance of patents with the IP correspondents. Note that during all of these steps, the business unit IP correspondents play a major interface 
role. For confidentiality reasons, secrete military patents are handled inside Thales. All other types, such as confidential patents, for which Marks \& Clerk was awaiting a defence accreditation at the moment of its creation, are outsourced. Marks \& Clerk therefore now provides all of the services needed for implementing Thales' IP strategy (except for secret military activities, which are marginal in the group). The result is a very pragmatic approach to IP management: Thales has handed over all of the purely legal aspects to its new entity, and keeps all of the strategic and technological decisions in-house. This pragmatism allows the company to cut costs and redeploy the legal capacity of patent management. On its side, Marks \& Clerk remains autonomous and offers services to other clients.

\section{5 - DISCUSSION AND IMPLICATIONS}

As we have shown, Thales has introduced a significant modification in the way it organizes its IP in an evolving industrial context. The next step involves using these empirical data to answer the fundamental questions of this research: Why should IP be outsourced? How should outsourcing of IP activities be organized, and how should the capabilities involved in this new organizational arrangement be managed? The answers to these questions can help us understand the decision to outsource and its theoretical and managerial implications. The aim is to explore the ramifications of IP outsourcing using the Thales case study and to analyze its implications for other firms or institutions. In other words, it involves going beyond the simple framework of outsourcing by showing what it can teach us about managing intellectual property in general. This brings us back to the question of making generalizations based on case studies, and in particular single case studies. Numerous works have focused on this question of generalization by looking at the impact that a case can make and how it can contribute to knowledge (Gomm et al., 2000; Stake, 1995; Yin, 2003). These studies outline a naturalistic generalization in the sense of inferring claims about a wider class of phenomena that go beyond a particular case (Evers and Wu, 2006). So far, case study methodology has provided the opportunity to improve existing knowledge by generalizing on theories rather than populations, which is the focus of statistical generalization.

\subsection{THEORETICAL IMPLICATIONS}

As mentioned above, previous research has successfully analyzed outsourcing based on transaction costs and capabilities. In line with the work of McIvor (2009), transaction-cost and capability-based approaches provide complementary analysis frameworks in the specific case of IPR management. However, outsourcing has never been studied with a focus on how IP is 
organized. The benefits of this kind of research are twofold: its main contribution concerns IP management, along with a greater understanding of the logic of outsourcing in the case of spin-offs.

\section{Improving IPR studies in innovation management literature}

The main contribution of our research concerns IP management. Four main benefits are worth mentioning here.

Firstly, our research adds to the emerging literature on IPR studies by focusing on firm level (Candelin-Palmqvist et al., 2012; Somaya, 2012). More precisely, it adds to the rare studies done on the ways of organizing protection. Apart from work by Granstrand (1999) on Japanese firms, research has mainly remained silent on the issue of organizing IP activity. Moreover, although Granstrand mentions the outsourcing of IP as a possible organizational design, no prior study has specifically examined IP outsourcing. Granstrand's study centres on a chronological characterization of the different ways of organizing protection in-house. The author pinpoints six typical stages. In the first of these, a manager organizes the protection with occasional help from a consultant. Granstrand goes on to explain how an IP Department is progressively structured to support the pro-active management of IP. In the last stage, a "Distributed Intelligence Culture Management" takes hold, with a focus on a strong patent culture and shared responsibilities. In this analysis, the use of external IP consultancy firms is simply mentioned in passing.

Secondly, our results outline a new division of knowledge and the need to develop new capabilities to deal with IPR. It adds to literature on identifying capabilities in the innovation field and especially in the IP domain (Mayer et al., 2012). Capabilities can be defined as the ability of a firm to manipulate is resources in order to attain fixed objectives (Amit and Schoemaker, 1993). It is important to reflect more deeply on the relationship between Thales and Marks \& Clerk in order to better comprehend the true motives for this outsourcing and its consequences on the various capabilities for dealing with IPR (Parhankangas and Arenius, 2003). As we have shown, a trigger for outsourcing was to cut costs by using a service provider. In line with a transaction cost approach, the Thales case clearly shows a choice between transaction and integration costs. As mentioned before the company was aiming to cut costs by $20 \%$ to $25 \%$ over a period of five years. This objective has been reached. We should point out here that Marks \& Clerk's fees were negotiated at the time of the initial 
contract to make this saving possible. However, the specific nature of IP assets does not make it possible to rely exclusively on a transaction-based approach. Other motives therefore need to be considered. The increasing legal complexity that we have pointed to in complex industries, and defence in particular, is intrinsically linked to the decision to outsource. Given the numerous disputes and strategic battles around IPR, particularly in the software industry (Suh and Hwang, 2010), the legal competences necessary to handle competitive relationships may seem far removed from Thales's prior technological core competences. In line with Mayer et al. (2012), Thales accesses the expertise of a specialized supplier who possesses occupational human capital based on patent legal knowledge.

In addition, within Thales itself, IPR management has been made more difficult by the fact that numerous international contractual arrangements are not governed by the same protection traditions (this involves exchanges between foreign business units that are regulated by different rules of play). There are therefore both external and internal factors that call for new legal capabilities.

Thirdly, our research underlines the complementarity of activities managed internally and externally. Although this complementarity has been studied for R\&D activities (Hagedoorn and Wang, 2012; Berchicci, 2013), no research has been envisaged regarding IP. In addition, we show how this complementarity works in practice through organizational and strategic choices (Lowman et al., 2012). The outsourcing in place clearly shows that not all IP activities have been handed over to the service provider, but only those relating essentially to the legal and administrative domains. Through this new set-up, Thales attempts to minimize the risk of finding itself drawn into large and costly legal battles outside its initial expertise, while ultimately retaining decision-making power over a whole range of strategic and technological choices. Significantly, the fundamental decisions to file, maintain, abandon, renew and grant licences are always made by Thales and are taken at the highest strategic level. This illustrates a close relationship between IP strategy and group strategy. Thales thus still tightly controls its patent management. In fact, the group delegates at least part of its IP to an outside firm so that it can focus on its technological capabilities in integration systems which are considered as a primary source of competitive advantage.

Thus, openness does not mean being totally dependent on a partner (Chesbrough and Teece, 1996). In accordance with Berchicci (2013) this balance between internal and external activities enables Thales to capture the benefit of external legal competences. In this sense, 
the decision to outsource constitutes a fundamental strategic decision based on a clear identification of future opportunities and the firm's capabilities. This implies a new organizational arrangement for managing IPR, involving a clarification of which kind of activity can be outsourced as a means of preserving its core capabilities. It also outlines the role of service organization in creating value in the outsourcing process (Lowman et al., 2012). From this point of view, the present case invites us to make a subtle analysis of the various capabilities involved in IPR management: technological, strategic and legal.

Fourthly, the results add to the literature on dynamic capabilities. From this perspective, their implications go beyond the simple issue of outsourcing. The study of this organizational approach allowed us to characterize the different types of capability currently necessary for managing IP. It gave us an opportunity to differentiate technological, strategic and legal capabilities. In particular, it showed the significance of new legal capabilities to tackle an increasingly complex legal environment. Our research thus underlined how important it is for a firm to be able to develop its resources and identify its core capabilities in a changing environment. Changes in the rules of play redefining the institutional environment, and the governance institutions in force increase this complexity but also generate an opportunity to create complementary legal capabilities that evolve along with the initial technological and strategic capabilities. In other words, our research points to a firm's ability to effectively coordinate and redeploy internal and external competences and therefore develop its dynamic capabilities (Teece et al., 1997). Although studies of dynamic capabilities are widely present in the innovation field, published works have not specifically centred on analyzing these capabilities in the precise field of IP management. Our research makes a first contribution in this area. Increasingly, studies raise the issue of devising IP strategy based on the products and nature of innovation. Some authors even argue that the boundaries of IP should be drawn according to innovation's potential modularity (Henkel and Baldwin, 2009). In this context, IP strategies are dynamic and co-evolve with innovative strategies. They should therefore be considered as a specific organizational capability that may go beyond simply creating value to increase the potential for profiting from innovation (Chesbrough and Teece, 1996) and to provide a better value appropriation.

\section{A better understanding of outsourcing in the case of spin-offs}

Along with providing insight into intellectual property management itself, our study deepens the understanding of outsourcing by focusing on the links between a spin-off and a parent 
company. As mentioned by Freytag et al. (2012), establishing a new organization like a spinoff can solve difficulties related to outsourcing. Two main contributions to previous studies can be outlined here.

Firstly, many studies have pointed to how new organizational forms are constrained by the characteristics of their founders (Hannan and Freeman, 1989). However, most often, spin-offs occur in the same industry and either create a replica of existing routines or extend them by modifying the original model. To our knowledge, there have been few studies of spin-off development outside the parent company's original sector, in particular industries towards services. The present case provides a very significant example. Here once again, a careful look at the specific nature of IP assets with a clear distinction, as we have shown in this case, between the technological and strategic dimensions on one hand and the administrative and legal dimensions on the other, makes it possible to explain this spin-off in a completely different sector. Indeed, published literature has not differentiated the various capabilities required to explain this kind of spin-off. Specifically, our findings outline a clear sharing of capabilities needed for managing IPR in complex industries, and the need to preserve a relationship between the new entity and the parent company to deal with this complexity. Maintaining these strong collaborative bonds is a way of ensuring that the capabilities needed for managing IPR in this type of industry are shared (Parhankangas and Arenius, 2003). Like the authors quoted above, we identify more quasi-outsourcing than fully-fledged outsourcing here.

Secondly, our study confirms the importance of human capital in the success of spin-offs. It is worth a reminder here that the founders of the consultancy firm came from the parent company. The managers of Marks \& Clerk personally ensure the transmission of skills, which minimizes transaction costs for both entities. In addition, by maintaining a network of Thales employees, communication is easier and the group's technical problems can be resolved, minimizing transaction costs ex-post. It is in fact clear that the decision to outsource also involves maintaining strong links with the group, both in the actual creation of Marks \& Clerk and the way it works. Ultimately for Thales, there is both a break and continuity, and the outsourcing can be seen as a redeployment of new capability within a new organizational entity with a strong legacy from the parent company. This naturally raises the question of organizational antecedents and is clearly a case of outsourcing via a spin-off, as mentioned earlier. Yet, when a new company is created from an existing entity, the effect is not neutral 
on the new organization, since continuity can restrict organizational diversity through the transfer of competences towards a newly created entity. This is exactly the point in this case. On an organizational level, rather than emerging from nothing, the new entity is a continuation of something that already existed, creating a kind of path dependence that minimizes risk (Helfat and Liberman, 2002). This spin-off draws on existing human capital and thus minimizes the risk of failure and the development of its capabilities, since the new firm already possesses a set of initial capabilities (Klepper, 2001; Parhankangas and Arenius, 2003). In addition, this new entity benefits from organizational antecedents coming from an international group with an established reputation for managing IP. Finally, Mark \& Clerk has long-standing expertise, including how to deal with IP strategy in the case of systemic innovations. This IP capability may be redeployed in other industries, such as telecommunications and electronics, where negotiating IPR is rather similar but with distinct differences regarding the lifecycles of projects and products. Thus, strong accumulated experience in the defence industry opens the door to a range of opportunities in rights negotiations with different multinational corporations, of which the Mark \& Clerk Group takes advantage from its locations in France and diverse countries like the UK, China and Australia.

\subsection{MANAGERIAL IMPLICATIONS}

Our study illustrates the direct managerial implications of managing IP. This in-depth analysis will be of interest to IP practitioners, as the detailed information it gives on a specific firm can provide a benchmark for managing IP activities. This may prove particularly useful given that IP practices are often considered confidential and are difficult to grasp. Most studies are based on secondary data (mainly patent data) but lack direct practical experience from case studies (Candelin-Palmqvist et al., 2012).

The Thales case illustrates how a firm can organize its industrial protection to gain a competitive advantage. It underlines the importance of combining technological, strategic and legal capacities to determine this advantage. The outsourcing presented here is only one possible configuration to understand how these capabilities can be combined. Their combination within integrated, quasi-integrated or outsourced organizational forms is a key issue for managers. Whichever solution is chosen, this case highlights the importance of the organizational aspect of IP and the capacity of re-ordering organization to deal with an increasingly complex technological, and legal, context. The managerial benefits are particularly obvious when practising open innovation that relies on actively managing 
property rights (Chesbrough, 2003). This open approach fosters the emergence of new technological markets centred precisely on exchanging rights. In these markets, the stakeholders are not only major groups, they are also SMEs, universities and research organizations (Lichtenthaler and Ernst, 2008). Thus, to develop their technologies externally and integrate external technologies, stakeholders in these markets need to develop and combine new capabilities that are technological, organizational and strategic. They need to clearly define which of these capabilities are crucial and how they can be developed. In this context, the Thales case provides a good illustration.

\section{CONCLUSION AND FURTHER RESEARCH}

To conclude, the Thales case is original in our view since it suggests that a new division of knowledge to manage IP is necessary and requires new technological, strategic and legal capabilities. This has two main implications for further research.

Firstly, this case has outlined new forms of governance and new IPR strategies in its particular industry. For this reason, complex industries, like the defence industry, which have been significantly reorganized, provide a particularly rich observation field. More generally, technological complexity, such as that linked to IPR and companies' mutations in these industries, raises questions about the way in which multinational corporations should (or can) undertake innovation and IP policy in Knowledge Intensive Sectors (KIS). Lastly, the role of new types of intermediation, such as the SEFs presented by Arora and Gambardella (2010) lead us to ask questions about new types of division of labour and governance that diminish the uncertainty of transactions. The intervention of Marks \& Clerk clearly represents a new way of coordinating resources initiated by main companies and managed by new players in the military defence industry. It remains to be seen whether these new forms of legal intermediation will spread to other types of industry and other KIS.

Secondly, our study outlines the importance of technological, strategic and legal capabilities and their dynamic dimension for IPR management. However, little is known about the effective organizational processes that play a significant role in dynamic capabilities creation. This effort of identification could be further developed within the field of strategic management with a view to opening the "black box" of these processes (Ambrosini and Bowman, 2009). Through identifying the details of these processes and their underlying micro mechanisms, a better understanding of the role of dynamic capabilities, resource creation and regeneration processes could emerge. 


\section{Acknowledgements}

The authors sincerely thank Christian NGUYEN-VAN-YEN, manager of Marks \& Clerk France, for his amiable collaboration and the accurate information he supplied. They would also like to thank the different members of Thales who agreed to meet them as part of this research. The original version of the paper benefitted from the useful comments of the GREDEG members Jackie KRAFFT and Frédéric MARTY. The authors would like to express their gratitude to Vincent MANGEMATIN for his valuable remarks. They also gratefully acknowledge the helpful comments and suggestions of the anonymous reviewers and of Jonathan LINTON, Editor in Chief. Usual caveat applies. All mistakes and errors remain our own.

\section{References}

Ambrosini,V., Bowman C., 2009. What are Dynamic Capabilities and Are They a Useful Construct in Strategic Management. International Journal of Management Reviews. 11 (1), 29-49.

Amit, R., Schoemaker, P.J.H., 1993. Strategic Assets and Organizational Rent. Strategic Management Journal. 14 (1), 33-46.

Amin, A., Cohendet, P., 2004. Architectures of Knowledge, Firms capabilities and communities, Oxford University Press, Oxford New York.

Arora, A., Fosfuri, A., Gambardella, A., 2001. Markets for Technology. MIT Press, Cambridge, MA.

Arora, A., Gambardella, A., 2010. Ideas for rent: an overview of markets for technology. Industrial and Corporate Change. 19 (3), 775-803.

Barney, J.B., 1991. Firm resources and sustained competitive advantage. Journal of Management. 17 (1), 99-120.

Blind, K., Edler, J., Frietsch, R., Schmoch, U., 2006, Motives to patent: Empirical evidence from Germany?. Research Policy. 35(5), 655-672.

Berchicci, L., 2013. Towards an open R\&D system: internal R\&D investment, external knowledge acquisition and innovative performance. Research Policy. 42(1), 117-127.

Cassiman, B., Veuglers, R., (2006). In Search of Complementarity in Innovation Strategy:

Internal R\&D and External Knowledge Acquisition. Management Science. 52(1)1, 68-82

Candelin-Palmqvist, H., Sandberg, B., Mylly, U-M., 2012. Intellectual property rights in innovation management research : A review. Technovation. 32 (9-10), 502-512.

Chesbrough, H., 2003. Open Innovation - The New Imperative for Creating and Profiting from Technology. Harvard Business School Press, Boston.

Chesbrough, H., Teece, D.J., 1996. When is vitural virtous? Organizing for innovation. Harvard Business Review. 74, 65-73.

Chinworth, M.W., Mowery, D.C., 1995. Cross-border linkages and the US defense industry: outlook and policy challenges. Technovation. 15 (3), 133-152.

Dosi, G., Marengo, L., Pasquali, C., Valente, M., 2008. Patents, appropriability and competition in complex products industries: an evolutionary model, Preliminary draft, septembre. LEM Working Paper.

Eisenhardt, K.M., 1989. Building theories from case study research. Academy of Management Journal. 14, 532-550. 
Eisenhardt, K.M., Graebner, M.E., 2007. Theory building from cases: opportunities and challenges. Academy of Management Journal. 50 (1), 25-32.

Ernst, H., 2003. Patent Information for Strategic Technology Management. World Patent Information. 25, 233-242.

Evers, C.W., Wu, E.H., 2006. On Generalising from Single Case Studies : Epistemological Reflections. Journal of Philosophy of Education. 40 (4), 511-526.

Felin, T., Zenger, T.R., 2013. Closed or open innovation? Problem solving and the governance choice. Research Policy. In press.

Freytag, P.V., Clarke, A.H., Evald, M.R, 2012. Reconsidering outsourcing solutions. European Management Journal. 30, 99-110.

Gambardella, A., McGahan, A., 2009. Business-Model Innovation : General Purpose Technologies and their Implications for Industry Structure. Long Range Planning. 43 (2-3), 262-271.

Goldenberg, D., Linton, J.D. , 2012., The Patent Paradox - New Insights through Decision Support Using Compound Options. Technological Forecasting and Social Change. 79(1): 180-185.

Gomm R., Hammersley, M., Foster, P., 2000. Case study method: key issues, key texts. Sage, London.

Granstrand, O., 1999. The Economics and Management of Intellectual Property. Cheltenham, Northampton, Edward Elgar.

Granstrand, O., 2000. The shift towards intellectual capitalism - the role of infocom technologies. Research Policy. 29(9), 1061-1080

Guichard, R., 2004. Recherche militaire: vers un nouveau modèle de gestion ?. Economica, Paris.

Guillou, S., Lazaric, N., Longhi, C., Rochhia, S., 2008. The French defence industry in the knowledge management era: a historical overview and evidence from empirical data. Research Policy. 38 (1), 170-180.

Hagedoorn, J., Wang, N., 2012. Is there complementarity or substitutability between internal and external R\&D strategies? Research Policy 41 (6). 1072-1083.

Hanel, P., 2006. Intellectual property rights business management practices: A survey of the literature, Technovation. 26 ( 8), 895-931.

Hannan, M. T., Freeman, J.H., 1989. Organizational Ecology. MA: Harvard University Press, Cambridge.

Helfat, C.E., Lieberman, M.B., 2002. The birth of capabilities: market entry and the importance of pre-history. Industrial and Corporate Change. 11 (4), 725-760.

Henkel, J., Baldwin C., 2009. Modularity for value appropriation: drawing the boundaries of Intellectual Property. Working Paper. 097, Harvard Business School.

Herscovici, A., 2008. Droits de propriété intellectuelle et échange d'archives musicales, in Terminal. Centre d'information et d'initiative sur l'informatisation, 102, 61-79.

Hobday, M., Rush, H., Tidd, J., 2000. Innovation in complex products and systems. Research Policy. 29 (7-8), 793-804.

Hobday, M., Davies, A., Prencipe, A., 2005. Systems integration: a core capability of the modern corporation . Industrial and Corporate Change. 14 (6), 1109-1143.

Huang, Y-A., Chung, H-J., Lin, Ch., 2009. R\&D Sourcing strategies: Determinants and consequences. Technovation. 29 (3), 155-169.

Klepper, S., 2001. Employee start-ups in high-tech industries. Industrial and Corporate Change. 10 (3), 639-74.

Kopp, P., 2006. Politique et gestion de la propriété intellectuelle dans le secteur de la défense. Rapport final à la consultation lancée par le ministère de la défense - Direction des Affaires Financières, Observatoire Economique de la Défense, Paris. 
Lamoreaux, N.R., Sokoloff, K.L., 1996. Long-term change in the organization of inventive activity. Proceedings of the National Academy of Sciences. 93 (23), 12686-12692.

Lichtenthaler, U., Ernst, H., 2008. Innovation Intermediaries : Why Internet Marketplaces for Technology Have Not Yet Met Expectations. Creativity and Innovation Management. 17 (1), 14-25.

Linton, J.D., Embrechts, M., 2007. MOT TIM Journal Rankings 2006. Technovation 27 (3), 91-94.

Linton, J.D., 2011. What Does Journal Fit and Focus Look Like: A Visual Representation, Technovation. 31(12), 613-614.

Lowman, M., Trott P., Hoecht A., Sellam, Z., 2012, Innovation risks of outsourcing in pharmaceutical new produtct developemnt, Technovation. 32 (3), 99-109.

Mayer, K., Somaya, D., Williamson, I., 2012. Firm-Specific, Industry-Specific and Occupational Human Capital, and the Sourcing of Knowledge Work. Organization Science. 23 (5), 1311-1329.

McIvor, R., 2009. How the transaction cost and resource-based theories of the firm inform outsourcing evaluation. Journal of Operations Management. 27, 45-63.

Mehta, S., Peters, L.S., 2007. Outsourcing a core competency. Research-Technology Management 50 (3), 28-34.

Moeen, M., Somaya, D., Mahoney J.T., 2013, Supply Portfolio Concentration in Outsourced Knowledge-Based Services. Organization Science. 24 (1), 262-279.

Mollas-Gallart, J., Tang, P., 2005. Ownership matters: intellectual property, privatization and innovation. Research Policy. 35 (2), 200-212.

Murmann, J.P., 2003. Knowledge and Competitive Advantage: The Coevolution of Firms, Technology, and National Institutions. Cambridge University Press, Cambridge.

Neuhäusler, P., 2012. The use of patents and informal appropriation mechanisms- Differences between sectors and among companies. Technovation. 32(12). 681.693.

Oudot, J.M., 2007. Choix contractuels et performances. Le cas des contrats d'approvisionnement de défense. Thèse. Université Paris I Panthéon-Sorbonne, Paris.

Oudot, J.M., Bellais, R., 2008. Choix contractuels et innovation: le cas de l'approvisionnement de défense. Innovations. 86 (2), 85-103.

Parhankangas, A., Arenius, P., 2003. From a corporate venture to an independent company: a base for taxonomy for corporate spin-off firms. Research Policy. 32 (3), 463-481.

Prencipe, A., 1997, Technological capabilities and product evolutionary dynamics: a case study from the aero engine industry. Research Policy. 25 (8), 1261-1276.

Reitzig, M., Wagner, S., 2010. The hidden costs of outsourcing: evidence from patent data. Strategic Management Journal. 31 (11), 1183-1201

Rivette, K., Kline, D., 2000. Rembrand in the attic, Unlocking the Hidden Value of Patents. Harvard Business School Press, Boston.

Roquilly, C., 2009. Le cas de l'iPhone en tant qu'illustration du rôle des ressources juridiques et de la capacité juridique dans le management de l'innovation. M@nagement. 12 (2), 142175.

Serfati, C., 2001. The adaptability of the French armament industry in an era of globalization. Industry and Innovation. 2 (8), 221-239.

Serfati, C., 2008. Financial dimensions of transnational corporations, global value chain and technological innovation. Journal of Innovation Economics. 2, 35-61.

Somaya, D., 2012. Patent Strategy and Management: An Integrative Review and Research Agenda. Journal of Management, 38 (4), 1084-1114.

Stake, R.E., 1995. The Art of Case Study Research. Sage Publications, London.

Teece, D., 1986. Profiting from technological innovation: implications for integration, collaboration, licensing and public policy. Research Policy. 15 (6), 285-305. 
Teece D., Pisano G., Shuen A., 1997. Dynamic Capabilities and Strategic Management. Strategic Management Journal. 18 (7), 509-533.

Suh. D., Hwang, J., 2010. An analysis of software intellectual property on the performance of the software industry in South Korea ?. Technovation. 30 (5-6), 376-385.

Wernerfelt, B., 1984. A resource-based view of the firm. Strategic Management Journal. 5 (2), 171-180.

Williamson, O., 1998. Transactions cost economics: how it works; where it is headed. De Economist. 146, 23-58.

Winebrake, J., 1992. An Analysis of Technology Transfer Mechanisms for Federally Funded R\&D. Journal of Technology Transfer. 17 ( 4), 54-61.

Yin, R.L., 2003. Application of Case Study Research. Applied Social Research Series. Second Edition. 34, Sage Publications. 